\title{
A multidisciplinary engineering summer school in an industrial setting
}

\author{
Peter Gorm Larsen*, João M. Fernandes ${ }^{\mathrm{b}}$, Jacek Habel ${ }^{\mathrm{c}}$, Hanne Lehrskov ${ }^{\mathrm{a}}$, Richard J.C. Vos ${ }^{\mathrm{d}}$, \\ Oliver Wallington ${ }^{\mathrm{e}}$ and Jan Zidek ${ }^{\mathrm{f}}$ \\ ${ }^{a}$ Engineering College of Aarhus, Aarhus, Denmark; ${ }^{b}$ University of Minho, Braga, Portugal; ${ }^{c}$ Cracow \\ University of Technology, Cracow, Poland; ${ }^{d}$ Hanze University Groningen, Groningen, The Netherlands; \\ ${ }^{e}$ Bang \& Olufsen a/s, Struer, Denmark; ${ }^{f}$ VSB - Technical University of Ostrava, Ostrava, Czech Republic
}

(Received 22 October 2008; final version received 19 June 2009)

\begin{abstract}
Most university-level engineering studies produce technically skilled engineers. However, typically students face several difficulties when working in multidisciplinary teams when they initiate their industrial careers. In a globalised world, it becomes increasingly important that engineers are capable of collaborating across disciplinary boundaries and exhibit soft competencies, like communication, interpersonal and social skills, time planning, creativity, initiative, and reflection. To prepare a group of engineering and industrial design students to acquire those capabilities, an international summer school that combined industrial design with different kinds of engineering disciplines was organised on the site of Bang \& Olufsen (B\&O) in Denmark. This multidisciplinary engineering summer school was attended by students from six European university-level teaching institutions and was supervised by teachers from those institutions and industrial experts from B\&O. The main aim of the summer school was to allow students to work in teams, composed of students from different knowledge disciplines and with different cultural backgrounds, with the purpose of developing innovative concepts and products, within a strong industrial perspective.
\end{abstract}

Keywords: multidisciplinary engineering; embedded systems; mechatronics; problem-based learning; industrial setting; innovation

\section{Introduction}

In an increasingly globalised world, it is paramount for the competitiveness of any company that its employees are capable of creating innovative concepts for new products and for the subsequent production process faster than today (Calvano and John 2003). In addition, the complexity of products tends to increase continuously. In order to master that complexity and at the same time produce these products faster, it is essential that engineers with different disciplinary and cultural backgrounds are able to collaborate efficiently in short windows of opportunity. In general, there is a significant demand from industry for engineers who can collaborate with stakeholders 
outside their own discipline (Skates 2003). Nowadays, the majority of higher education institutions educate students in one specialist discipline, and as a consequence, when they enter industry, they face major difficulties in adapting to multidisciplinary project teams. A study of engineering graduates' perceptions on how well they are prepared to work in industry confirms that one of the key weaknesses in their education is the ability to work in multidisciplinary teams (Martin et al. 2005). Engineering graduates are typically lacking skills for collaborating with professionals with different disciplinary backgrounds, because they have problems in understanding the significant design constraints for the other disciplines, and as a consequence are often unable to come up with optimal and innovative solutions. Furthermore, students are often unfamiliar with the complexity of 'real world' problems and how to approach them.

Additionally, the opening of international markets leads to the necessity of new competencies and skills for engineers (Lucena 2006). Due to the increasing number of companies that outsource their engineering activities to partners located in emerging economies, there is a tendency towards a change of the role/profile for engineers to fulfil tasks such as negotiating requirements, architecting systems, preparing contracts, planning and managing projects, controlling tasks, verifying solutions against their specifications, managing team work, coaching and training, or communicating a project's result. In industry, it is becoming quite common for companies to follow a global development approach and consequently carry out their engineering activities at distinct sites, for taking advantage, for example, of their different time zones (Ebert and Neve 2001).

A group of six European university-level institutions, in collaboration with an industrial company, had organised a summer school, entitled 'Conceptual Design and Development of Innovative Products', in order to prepare the students for the globalised world. The summer school, which brings innovative dimensions to higher education, was conceived taking into account the following essential principles:

- Team-oriented activities: the students work collaboratively in teams to develop an engineering product.

- Multidisciplinary approach: the teams are composed of students with different disciplinary backgrounds, whose skills, knowledge, and experience are important to combine in order to achieve the project's goal.

- Multicultural approach: the teams are composed of students from different countries.

- Problem-based learning: learning is centred on the students, using open assignments with several possible valid solutions, and the teachers act as tutors of the assignments.

- Intensive schedule: the summer school lasts for a relatively short period of time, and students work exclusively on their projects during five days a week.

- Industry-oriented: the summer school takes place in an industrial setting and the assignments are closely connected with the requirements of the industrial partner.

The main aim of this summer school is to let students with different technical backgrounds acquire a better understanding and respect across disciplinary, national and cultural borders. This was achieved by letting the students work in multidisciplinary teams to develop innovative ideas and products, within a problem-based learning environment and a strong industrial perspective. As stated by van Kasteren (1996), working in multidisciplinary projects has been demonstrated to be an excellent method to improve interdisciplinary thinking and studying skills.

The summer school was planned to take the students through the innovation and creativity processes, with the aim of designing a product from the very birth of an idea to the construction of a prototype and the planning of the interfaces between the different disciplinary parts. Through these processes the students experience the importance of creative and innovative competencies in 
all development phases. Students also learn how different techniques help to stimulate creativity and on supporting the innovative focus in the act of designing (Lawson 1980, 2004).

Problem-based learning (Savery 2006), in short PBL, was adopted as the main pedagogical approach during the summer school. Student teams received different realistic open assignments (called design briefs) and based on these, had to come up with a candidate solution. The fact that this summer school was held on the premises of a company rather than in the traditional lecture rooms gave an extra level of motivation and engagement for the students.

The summer school was primarily financed by a successful application to the European ERASMUS Intensive Programme. In addition, the hosting company Bang \& Olufsen found the summer school so interesting that they both supplied a financial contribution as well as the time for different internal stakeholders during the summer school.

The paper starts with a brief overview of the participants in Section 2. In Section 3, we describe the learning space and in Section 4 the programme that was delivered at the summer school is discussed. Section 5 presents the new aspects deployed at this summer school and Section 6 provides details about the evaluation of the summer school. The paper is completed in Section 7 with concluding remarks, including some ideas about how we think others can get inspiration from this learning and teaching experience.

\section{Participants}

This summer school was organised by the Engineering College of Aarhus (Denmark), the VŠB - Technical University of Ostrava and Tomáš Bata University in Zlín (Czech Republic), the Cracow University of Technology (Poland), the Hanze University Groningen (The Netherlands), and the University of Minho (Portugal). Each institution provided one teacher and up to five students for the summer school. Bang \& Olufsen (B\&O), a Danish manufacturer of exclusive audio systems, televisions, loudspeakers, telephones and digital media products, was also highly involved in the organisation, providing its facilities and its experts for the realisation of the summer school.

\subsection{Students}

At each institution, a teacher was responsible for selecting students to attend the programme based on their English language skills, their technical skills, and their motivation to take part in a multidisciplinary project. Twenty-eight students were selected to participate. The level of the students participating in this summer school was a combination of B.Sc. and M.Sc. students from the different partner institutions. The students' average age was 23.5 years. They had around one year left of their studies and their areas of expertise covered mechanical engineering, electronics engineering, software engineering, industrial design, and human technology.

\subsection{Teams}

Six student teams were created: four teams of five students and two teams of four students. The teachers were responsible for defining the composition of the groups of students, with the aim of avoiding students from the same educational institution in the same group and having the students spread as widely as possible across the different disciplines. This initial grouping results in teams where each individual contribution is potentially maximised, as suggested by Maskell and Grabau (1998). 


\subsection{Teachers}

The partner institutions provided the summer school with a total of six teachers. They were responsible for defining the summer school programme and the (application of the) pedagogical approach. They also gave guidance and technical support to the students during their activities, and helped the students in the management of the projects, namely in deciding changes in the composition of the groups, when appropriate. Additionally, teachers were responsible for a $1 \mathrm{~h}$ lecture on a topic considered relevant for the programme. The topics addressed in the programme were: Human Technology Interaction, Innovation and Creativity, Systems Engineering, Requirements Engineering, Product Development, and Virtual Instrumentation. Finally, teachers were in charge of preparing several questionnaires for the students to fill in, with the purpose of evaluating the quality of the activities developed during the summer school.

\subsection{Industrial experts}

Several experts from B\&O also participated actively in the programme. They were in charge of clarifying the company's principles and mission, design process, portfolio of products, professional careers, research activities, and sales strategy. In addition to presentations about these subjects, $\mathrm{B} \& \mathrm{O}$ experts took an active part in guiding the students in modelling their creative concepts, and a larger group of $\mathrm{B} \& \mathrm{O}$ experts gave feedback to the students on their work after the first week and during the final presentation (at the end of the third week).

\section{Learning space}

The working space for the summer school, whose floor plan is depicted in Figure 1, was located in B\&O's industrial facilities in Struer. The available space $(14 \mathrm{~m} \times 19 \mathrm{~m})$ was divided into two main areas. At the front, there were basically two tables and eight chairs, used by teachers to prepare their work, and a space, organised like an auditorium, that was used for lectures and seminars. Some tables were also used to install the printers used for supporting activities, for both students and teachers. This turned out to be an efficient learning space for the summer school.

The back space was reserved mainly for student activities. Each project team had a reserved $4 m \times 4 m$ cubicle for their activities. The cubicles were open, without any door. There was a common working area between the two lines of cubicles, for all the project teams, where students could build their prototypes, using tools and materials available there. There was an extra room with special ventilation and soldering equipment. The students had also access to a $\mathrm{B} \& \mathrm{O}$ prototyping team that could help with producing physical prototypes in different kinds of materials.

Additionally, a staff-only room was available in the same building at a different floor. This provided a quiet and private setting that was put into use for discussing student and project teamrelated issues, discussing proposals for changes that were deemed sensitive, as well as personal communications.

From a teaching-learning perspective, we believe that the easy access to teachers, experts, peers and the Internet in the working space was essential. On the one hand, students were having concrete experiences through direct, explicit forms of feedback, and information when they needed so or needed to. On the other hand, the close collaboration and ease of access to assistance, implicit feedback, and modelling examples (in the form of both fellow practitioners and reference projects on innovation), facilitated the students' process of discovery and creativity by the transference of implicit knowledge. 


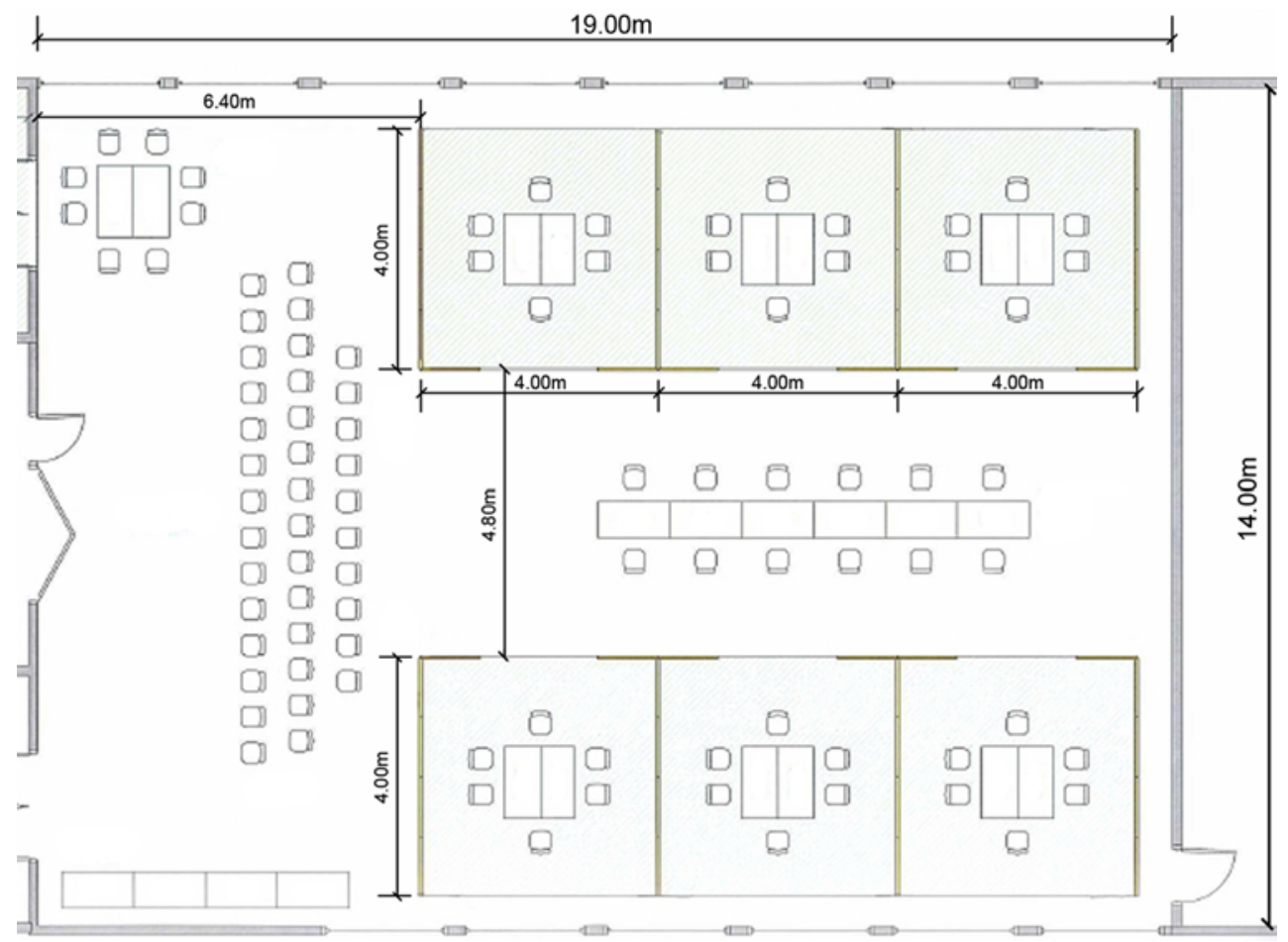

Figure 1. Layout of working space.

We wanted the project teams to feel like they were an external consultancy team in competition with other consultants. The cubicle set-up was really successful, the balance of the teams' privacy and overall room openness allowed both strong team/competitive experience, but still gave the whole summer camp a group experience. The amount of cross-pollination of ideas among teams was at a good level, having a shared 'building space' meant that techniques could be shared.

\section{Summer school programme}

\subsection{Main characteristics}

The curriculum of a summer school often resembles courses at a university in traditional classroom settings. In most cases, it is teacher-led with lectures and practical exercises, roughly equally divided. Moreover, the curriculum is composed of a set of educational units, which are connected with the main subject of the summer school.

This summer school was innovative in the sense that students were taken out of their conventional classroom environment with substantial portions of teacher-led expositive learning to a real industrial setting with a PBL approach in a multifaceted, multidisciplinary, and multicultural setting, using learning units rather than teaching units. The programme was structured to have approximately $10 \%$ of lectures and $90 \%$ of team work, and it took place over three weeks at B\&O’s industrial facilities in Struer, Denmark, during June-July 2008.

As already stated, the main aim of this summer school was to let students with distinct technical backgrounds acquire a better understanding and respect across disciplinary, national and cultural borders. Thus, students worked in multidisciplinary teams to develop innovative products, within 
an industrial environment. In accordance with this aim, the learning objectives for the summer school are that each student after a successful attendance should be able:

- to co-operate in multidisciplinary/multicultural team activities;

- to participate in a conceptual design process;

- to demonstrate interpersonal skills during team development;

- to propose and justify the value of new innovative technical solutions;

- to conduct disciplinary analysis of a real-world industrial problem;

- to present analysis to stakeholders with different backgrounds; and

- to design disciplinary interfaces to other disciplinary products.

The core issues related to the learning process within the current summer school can be represented in the form of an informal model, as depicted in Figure 2. The main subject of the learning process is the student, but other participants are also involved, namely peers, teachers and B\&O experts, who fulfil the role of knowledge transfer to students. The learning process is affected by inputs, controls, and mechanisms and generates outputs. The inputs of that process, shown in the left-hand side part of Figure 2, are the exercises and the design briefs, i.e. assignments for the project teams, the lectures given by teachers, and the seminars given by $\mathrm{B} \& \mathrm{O}$ experts. In order to enable the students to get access to the newest internal B\&O developments, all students were required to sign a Non-Disclosure Agreement (NDA).

There are some mechanisms and resources, shown on the bottom part of the figure, which are used in the process: PBL as the pedagogical approach, the learning space provided by $\mathrm{B} \& \mathrm{O}$ facilities, and the materials, tools, and support by a B\&O prototyping workshop for making the prototype. The process is controlled by several controls, shown in the top part of the figure: the questionnaires, the teachers' coaching and feedback, and feedback given by B\&O experts. Finally, the outputs of the learning process are, in this case, the product concepts and new technical skills, knowledge, experience, and soft competencies acquired by the students.

\subsection{Design briefs}

Students got their main assignment in the form of design briefs, which described in general the main requirements of the product to be developed. These design briefs were specially developed

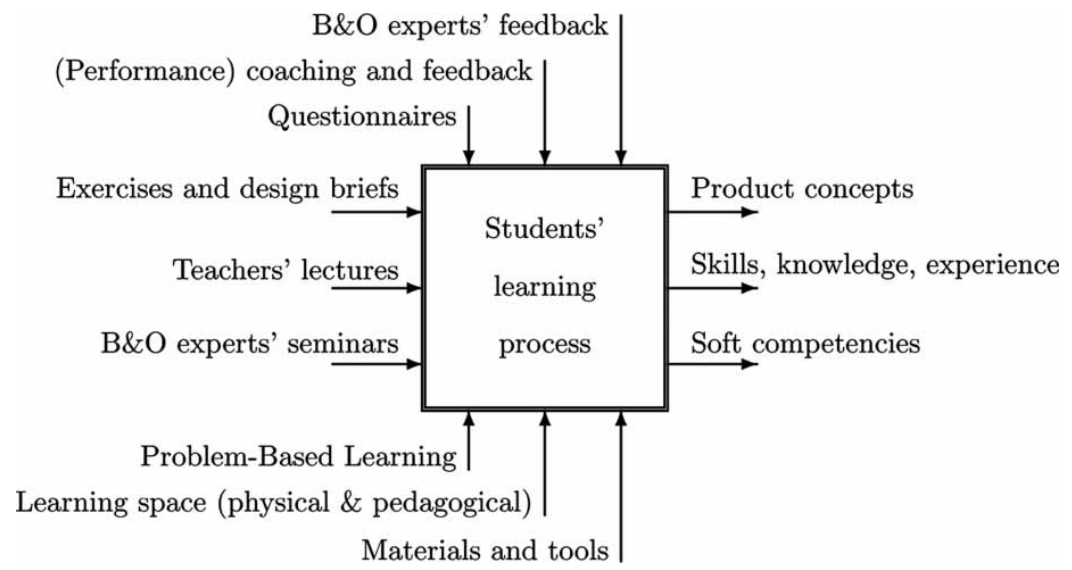

Figure 2. Model of the students' learning process. The learning process is affected by inputs, controls, and mechanisms and generates outputs. 
for this event by B\&O. Considerations included:

(1) Areas of genuine interest. The company is looking at these areas (amongst others) and was genuinely interested in the result of these projects;

(2) Projects were selected that would require an even mix of engineering input, i.e. physical products that have mechanical movements and screen/software elements (for example, a media centre or limited functional object such as TV stand would focus on software or design and thus limit the summer school intention); and

(3) Balance of openness and constraints. The design briefs attempted to give enough constraints that a strong direction could be seen, however, enough freedom for the students to explore within their own discipline. For example, just asking for a new stereo would require the student to spend more time in the early concept phase (what kind of stereo, what range of positions, etc).

In this summer school, there were three different briefs; one for each of the two project teams:

(1) Re-birth of the portable stereo.

(2) Content explorer.

(3) $\mathrm{B} \& \mathrm{O}$ interoperability.

All the briefs are characterised by being open in nature such that many different candidate solutions could be chosen. Figure 3 shows the title, the background, and the tasks of the first design brief that students were supposed to conduct. The two other briefs follow a similar structure.

\subsection{Schedule}

The three-week programme was divided into three stages, during which the students had to accomplish several tasks in order to conceive an innovative product concept. The stages are as follows:

- Stage 1: students practise and expand creativity and teamwork skills;

- Stage 2: students elaborate on the idea of a concept for a product;

- Stage 3: students work on the product, namely on its prototype, its design, and its technical documentation.

The first week focused on creating an idea for an innovative concept for a mass-market product, by using creativity, and on developing a proof-of-concept. The remaining two weeks took that concept and prototype forward to the point where the actual production process for the product could start to be prepared. In this period, different disciplinary analyses were conducted and, in particular, the interfaces among the different disciplinary parts were agreed upon and described precisely.

The programme also included time for some social events, which were deemed important to build social links among all participants of the summer school. Those events took place preferably during the evening hours and during the weekends.

\subsubsection{Week 1}

Since the first week was defined as a 'preject' (Darsø 2001), it was organised as a series of sessions aimed at supporting the flow of ideas. The reason for this option is to form a pool of ideas in order to broaden the potentials of possible solutions to the given briefs. These sessions are fundamental to prepare the mindset of the students to start thinking in possibilities and problems rather than solutions, sometimes also defined as 'out-of-the-box thinking'. 
Brief: Re-birth of the Portable Stereo

Background: Portable stereos have been an important product for many years; they have allowed music and talk radio to be heard in almost any location. While often still called portable stereos, they often never leave the home. As well as being versatile in their location, they are also used in different ways by different people. Uses include:

- 2nd stereo, for kitchen, bedroom, etc.

- Main stereo for younger generation.

- Outdoor stereo for garden.

- Outdoor stereo for beach, sports, etc.

While still popular, portable stereos are increasingly seen as less attractive due to the emergence of personal MP3 players, mobile phones, and home computers. However, there are still many situations where these are not an ideal solution.

Task: Bang \& Olufsen is interested in developing a new portable stereo. This should be ideal for the same broad situations/users as typical portable stereos however should use the benefits of the digital world such as hard drive technology, wireless, 3G Internet connection, etc.

- Primary function of a portable audio player.

- Large local collection and ability to stream content from web and/or home server.

- Unique, intuitive and attractive physical interaction.

- Stand/position to enable placement in multiple locations/surfaces.

- Appropriate for a high class beach party to a basketball court in LA and still be $\mathrm{B} \& \mathrm{O}$.

Figure 3. Example of a design brief given to project teams.

The basis of the preject was the Innovation Process Model proposed by Darsø (2001), which defines four important dimensions to the preject. All dimensions should be addressed in the preject: (1) knowledge (all existing knowledge), (2) ignorance (knowledge unknown to the team), (3) relations (between team members) and (4) concepts (the framing of ideas). More details about the preject are provided in Section 5.

To stimulate the knowledge dimension, and based on a given design brief, the teams went through a few warm up exercises. These included a Post-it ${ }^{\circledR}$-based exercise to find and structure the knowledge the team had about the problems related to the brief. The aim of the exercise was to generate ideas based on the existing knowledge in the team. This also included a small project where the students had to look at a new product from a marketing perspective (who/where/why/what does the shop say). The aim of this exercise was to introduce and give context to who the target customer was, how this influences other considerations all the way through to very quick mock ups in card/foam. This process helped set a pace and introduced them to presenting to a large audience.

Moving on to focus on the ignorance dimension, the teams were asked to create a series of 'baton stories'. This exercise deals with storytelling, and exercises the ability to use the imagination and to pick up on a given story and to develop new surprising aspects to it.

The relationships between team members had a direct influence on the capability of getting the flow of ideas to work in the team, as well as on the performance of the team. Therefore, an exercise using LEGO ${ }^{\circledR}$ pieces was introduced. In the exercise, three teams were to build a house with a garage and a landing platform, a car, and a helicopter. Team 1 was responsible for building the house, team 2 was in charge of constructing the car, and team 3 was asked to build the helicopter. The teams were also expected to decide among them who was responsible for building the garage, in such a way that the car could fit in it, and the platform, so that the helicopter could land there. As the three tasks had to be integrated and as there was a limited amount of pieces as well as a set 


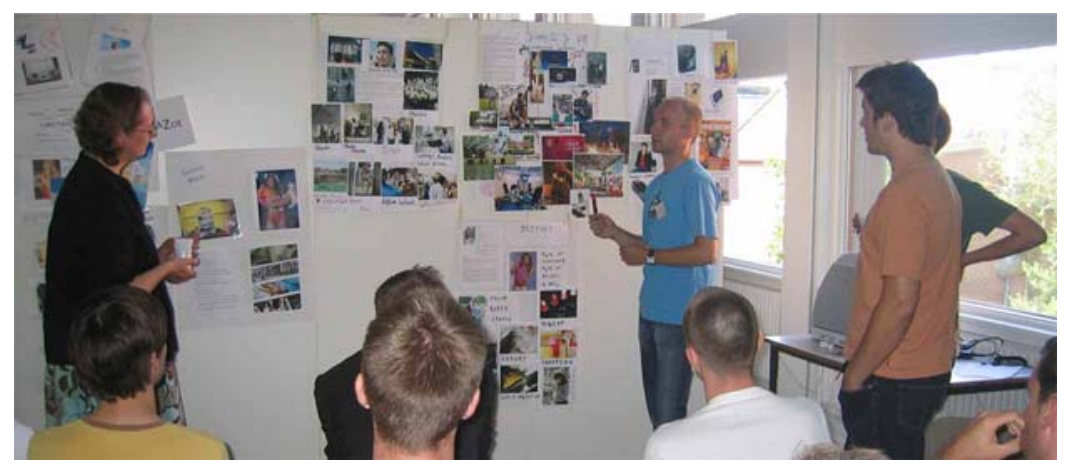

Figure 4. Students presenting their personas.

time limit, the possibility of getting a result needed a great deal of communication, planning, and negotiation within each team, as well as between teams.

To motivate the generation of more ideas for the briefs, the students were introduced to the notion of concepts. This was accomplished by adopting quick concept designs and later by moving on to working with personas, created through the idea writing technique. The personas were then given an environment by creating visual scenarios (collages), as shown in Figure 4. Each team generated more ideas for its specific brief, transformed those ideas into a product concept, and constructed a 3D prototype. The physical shape and aspect of the products took their form and were ready for the first project presentation.

Overall, this week was very productive, and students rapidly gained familiarity with the other team members (and also with the members of other teams). The pedagogical scheme used during this week was a teacher-directed PBL with one task and one deadline (Maskell 1999). This was done because the focus was to make students think creatively and innovatively outside a pure technical context. It was important for the students to be visionary, and not to be constrained too much in their technical disciplines (Skates 2003).

\subsubsection{Weeks 2 and 3}

During the last two weeks, the students took the concept and its prototype forward, in order to get to the point where the actual production process for the product could start to be prepared. Students conducted different disciplinary studies and, in particular, they described in a more precise way the interfaces among the different disciplinary components of the product. These weeks followed a more pure PBL approach, with a technical focus on developing the prototype.

In these two working weeks, the working hours were from 8 am to $5 \mathrm{pm}$. Week 2 started with a presentation by the students of their product concepts to an audience mainly constituted of B\&O experts, which gave important feedback for students on some aspects of their concepts.

Each project team appointed a student as its project manager, who was responsible for planning future work: for identifying tasks, for estimating the working time for each task, and for assigning tasks to team members. During this week, there was also some time scheduled for lectures by teachers and seminars by $\mathrm{B} \& \mathrm{O}$ experts.

Week 3 was mainly focused on the product development, as illustrated in Figure 5. Students had prepared all product components (form design, mechanism, user interface, etc.), the product documentation, an extended version of the prototype and the final presentation. On the last day, each team explained its product concept and presented its final prototypes to B\&O stakeholders, teachers and journalists. 


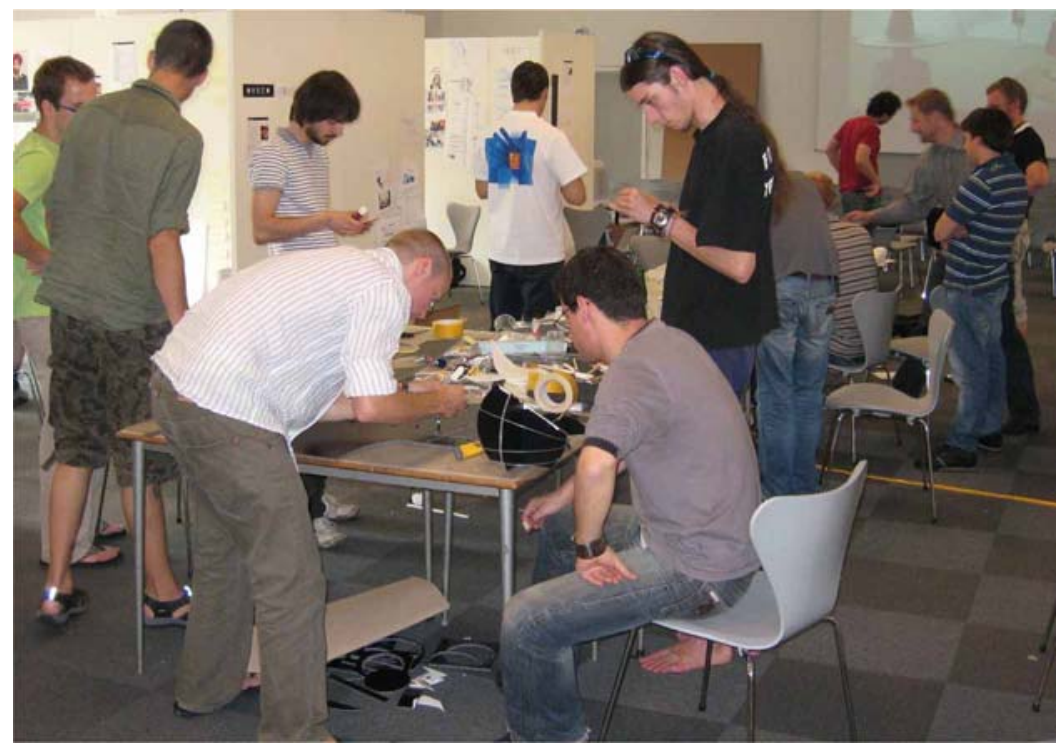

Figure 5. Students working on their prototypes.

\section{New aspects of the learning process}

\subsection{Learning-centred environment}

In recent years, the durability of knowledge is progressively decreasing. One cause is the profound presence of and access to the Internet. Its major impact on business models and internationalisation has changed our society and economy. In accordance, industry needs to anticipate current and future developments. To be successful under these changing circumstances, technology and business innovation need to improve the process of cross-pollination of ideas. This requires different kinds of managers and professionals: individuals who can be characterised by having a deep understanding of at least one field of specialisation supplemented by generic (technical and business) knowledge and skills to be able to stretch out towards other disciplines. Compare these 'T-shaped' individuals (Kelley and Littman 2005) with the T-shaped managers as introduced and described by Harvard Business Review (Hansen and von Oetinger 2001) focussing on the management and transfer of knowledge and organisational learning. The intention is that a broad (and usable) knowledge base will lead to successful intersectional innovation (for instance, lead to design that integrates the breadth of knowledge of many fields). Although history has delivered some remarkable examples of 'T-shaped' individuals, education of the last century had a complete different focus.

Further, research in cognitive neurosciences provided new insights on learning and the human brain with implications for teaching (Zull 2002, Caine et al. 2005) and the design of learner-centred environments (Bransford et al. 2003, Donovan and Bransford 2005).

Regarding current developments, the demands and desired outcomes of education are being redefined (Seng 2000). Programmes like the lifelong learning programme (LLP) of the European Community are illustrative of this wind of change. ${ }^{1}$ The same goes for the current summer school, which is an intensive programme within the context of LLP.

Probably one of the most striking features of new learning is the shift in the role of both teachers and students. In the last century teachers happened to be the sole source of knowledge. Nowadays, 
in our current knowledge society, teachers are no longer the sole source of knowledge (but one out of many).

In the early days, teachers were force-feeding knowledge into the minds of their students ${ }^{2}$ (and lots of teachers still do by loading the students with lots of presentations). However, learning is a natural process that happens in social encounters. Knowledge dissemination should be based on modern learning insights, like (social) constructivism, recognising the fact that students build on previous acquired knowledge and skills. The starting-point for teaching-learning should be what the student knows and extending the competencies. The main principle is that not teaching, but learning is central. Therefore, the learning-environment should reflect a shift from being teacher-centred towards being learning-centred.

Education had a tendency to focus on one field of specialisation or knowledge area and deal with most single-faceted assignments with little direct relation to the real world. However, current real world problems often can be characterised as multi- $\times$, i.e. they are multifaceted and need a multidisciplinary and multi-method approach, and most likely there is a space of candidate solutions. The learning environment should facilitate a multidisciplinary approach (e.g. project teams, communities of practise/practitioners) to be able to deal with open assignments that have a direct relation to the real world and also show a strong resemblance to 'real world' problems.

PBL is an innovative educational approach that is widely implemented in higher education and 'in which complex problems serve as the context and the stimulus for learning.' (Major and Palmer 2001). PBL is promising because it is based on modern insights on learning, i.e., constructive, self-directed, collaborative, and contextual (Dolmans et al. 2005).

\subsection{Focus on innovation}

The innovation process model used during the first week of the summer school requires a special phase within the project. This phase often is referred to as the preject (Darsø 2001) and it is particularly important to include in innovative and creative projects. The aim of the preject is to stimulate divergent thinking and the process therefore focuses on searching, exploring, developing and unfolding ideas to create a base for innovation. In the preject, it is important to make use of the synergy within the group to keep the ideas flow in order to create a 'pool' of ideas. The preject is often experienced as a very productive period and for quite a few students in the summer school also a very challenging one, as the main rule for the preject is never to say 'no', but rather to keep accepting and building/adding on to the ideas through association.

The preject needs another type of leadership and another mindset than that of a traditional project (Darsø 2001). The group members are made aware of the different roles of leadership that nourish activity in all four dimensions of the innovation process model mentioned in Section 4.3.1, i.e., knowledge, ignorance, relations and concept. No one can take care of all four dimensions in one project. It is the responsibility of all group members, which means that all should take part in the leadership of the preject by taking on a specific role or 'hat', as for example the thinking hats proposed by de Bono (1985). The roles or hats can profitably be rotated between the group members as the process moves along.

The goal of the preject is to point at relevant directions for innovative designs or strategies as potential answers to the brief. It is used to identify a number of potential concepts that can be taken into a convergent phase for further investigation. The convergent phase, as opposed to the divergent phase, therefore deals with activities like comparing, classifying, examining, analysing, eliminating, synthesising and selecting between the ideas from the pool. The aim here is to qualify decision making and to finally define the project and make it ready for detailing and production. In this phase more traditional project managing tools were used, and the roles in the group can now be split into experts led by one project manager. 
We found that using the pre- and project model as a base for PBL with an innovative focus, successfully supported the aim of working in creative and innovative processes in the summer school. Keeping the students focused on the divergent and the convergent phases and the particular activities taking place in each of these phases, trained them to switch from chaotic and creative processes to processes of decision making, planning and managing. In reality both situations are existing in project work - they live parallel 'lives' so to speak. In order to make sure that progress through the design work took place, we found that the pre-/project model offered a visible diagram for the 'brain' activities, that students could refer to and agree on as they moved along the specific phase of the project. As the project moves along more and more decisions are made and changes become increasingly difficult and expensive.

\section{Programme evaluation}

The summer school corresponds to a five ECTS-point course for all the participating students and their performance was evaluated (fail/pass) at the end of the period.

In order to assess the impact of the summer school on the different stakeholders different questionnaires were produced and filled out.

\subsection{Students' evaluation}

In order to find out whether any adjustments to project team composition or programme was necessary small questionnaires was filled out after the first and the second weeks.

On the first day of the second week, students filled in a questionnaire to help teachers to understand if during the first week teams did indeed work as teams and if students were comfortable with the learning experience. The open questions regarding this issue were the following:

(1) What did you enjoy most during the 1st week?

(2) Do you think your group is working cooperatively?

(3) Do you feel comfortable in your team?

(4) Do you think that you are positively contributing to your group? If not, please explain why.

(5) Do you think that some of your group's members are not giving their best? If yes, please explain why.

(6) Do you think that your group needs a leader? If yes, do you feel that you could take that role?

Based on the answers given by students from a team it was possible to detect that they were having problems with team spirit. After meeting with the relevant parties, all agreed on swapping two students (with the same design brief, nationality and technical background). This swap was necessary because of personal issues but it was successful in reestablishing team spirits. In essence this could be seen as the presence of a student who went into a defensive mode being placed in a context where he had moved too far out of his comfort zone. Under most circumstances one would expect more students to react in this fashion. We distributed a similar questionnaire on the first day of the third week to check if during the second week teams felt they were working as teams and if students were comfortable with the learning experience. The answers to this questionnaire did not reveal any major problem, so no changes were proposed in group composition.

Also during week 2, two groups with the very same brief were merged. The merge was done after a careful discussion with the members of both groups.

These two examples on changes in groups are similar to the reality that the students will most probably face when working in industry and that are difficult to reproduce in traditional classroom settings. We believe that the challenges faced by students on these issues contribute to 
the acquisition of important soft skills that are highly appreciated by industrial companies. We found it is easier to handle those challenges in the type of learning environment adopted for this summer school, due to its industry-oriented and problem-oriented characteristics.

The full summer school was evaluated by a final questionnaire at the end of the third week. Here questions were grouped into a number of categories:

(1) Identification data

(2) General information

(3) Organisation of the summer school

(4) Contents of the summer school

(5) Social events

(6) Problem-Based Learning (PBL)

(7) Benefits, suggestions, and improvements.

In addition, a peer and self assessment were carried out for all the students at the end of the summer school.

These final evaluations showed that the students felt that they had gained a lot from participating in the summer school. Almost all of them expressed that it had been so much fun that they would like to do it again if they had the chance.

Aspects concerning the organisational side were rated on a scale of 1-5, 1 being 'unsatisfactory' and 5 'very good'. Quantity of information received about the summer school received the lowest average rate (3.8). Food and drinks provided the highest average rate (4.6).

On the contents side of the summer school, marks were granted on the same scale and they were also rather high. Here the highest one was the possibility to interact and to discuss problems and solutions (4.6) and the lowest one was the quality of the lectures and seminars held by the teachers (3.3). Here the marks ranged a lot between the different students, where some of them felt that the presentations were not geared enough towards the actual assignments, whereas others felt that the generality of the presentations gave them insight into other disciplines. However, this is definitely an area with improvement potential for next year's event.

It is also interesting to note that the students found the approach followed in the first week more useful (4.1) than the second and third week (3.5).

With respect to the social events, they were welcome for socialising with the rest of the students. All events were generally well received, moreover some suggestions for improvement were given.

\subsection{Industrial partners' evaluation}

Right after the final presentation by the end of the summer school all attending B\&O stakeholders received a questionnaire to capture their impression of the results delivered by the students. All of them felt that the outcome was very impressive during a three-week event and as a consequence everyone felt that the summer school should be repeated in the summer of 2009. They were mostly impressed with the quality of the innovative ideas and their presentations, the animations and prototypes. Suggestions for improvements for next years event included:

- more depth in the technical analysis (in particular from the technical experts but also from a few of the managers);

- more multidisciplinarity (including cost and marketing analysis).

Depending upon the position of the $\mathrm{B} \& \mathrm{O}$ stakeholders the most valuable outcome of the summer school was seen to be the new ideas, the recruitment potential and the inspiration from young people. 
Finally these stakeholders were asked to evaluate how important different skills obtained during the summer school would be for their new employees. All of these were rated very highly, but it is worthwhile noting that the highest rated one was team working experience.

\section{Conclusions}

We believe that the summer school presented here was successful for all stakeholders involved. The delivery of the summer school achieved the learning objectives and it confirmed our belief that the competencies obtained here will be valuable for the students in their future careers. It was amazing to see how far the students were able to come with their complementary capabilities. Without the kind of open assignment and focus on innovation we believe that this would not have been possible.

It is envisaged that similar multidisciplinary courses for some of our institutions internally and in addition for industrial organisations who wish to increase their skills with better collaboration about innovative ideas faster than today. In this way this summer school will turn into a lifelong learning project not limited to university students.

A challenge for repeating the concepts of the current course in a regular university setting is to recreate the intensity of the summer school. Several challenges can be envisaged in trying to make similar courses an integral part of regular curricula of universities. However, we believe that it should be possible to recreate a learner-centred, open learning environment offering a multidisciplinary and possible multicultural context, with real world, multifaceted, open assignments, providing students with easy access to skills, knowledge, and experience of teachers, experts and peers. Furthermore, we are convinced of the benefits for all stakeholders involved, including teaching staff. One challenge would be the ability of teachers (and students, too) to work in such an open environment where they can be interrupted continuously (see Figure 1 for a feasible, but workable lay-out). Next, course programming, scheduling and tuning should be done in close collaboration with all partners involved (e.g., industry, small businesses, research organisations, innovation institutes).

Similar multidisciplinary courses with industrial involvement and real world, open assignments have already been delivered at Hanze University. The results of these courses are promising from both a pedagogical and didactic point of view. For instance, at 'Value in the Valley'3 students work as project members in multidisciplinary teams on real world problems. Industrial experts, university teachers and more experienced peers act as their coaches. Students' learning takes place as a result of experiences gained through the process of participating actively in a community of practitioners (Lave and Wenger 1991), consisting of experts, teachers, and peers. Another example comes from a Human Technology course that was set up and carried out in close collaboration with TNO ICT ${ }^{4}$ in which multidisciplinary project teams of students had to develop conceptual models and design prototypes with respect to new gaming concepts in which user groups with disadvantages due to functional limitations will get compensated in order to have equal gaming chances. Both experts and teachers acted as coaches and provided feedback on the work in progress. Furthermore, meetings and lectures took place at both the university and institution's premises. Chances are high that the project result, a game in which blind players will have equal chances against players with normal vision, will be further developed by TNO ICT, Visio Haren ${ }^{5}$, and of course students.

A community of practitioners in which newcomers merge into its practises and work side by side with (more) experienced members extends the concept of the master-apprentice relationship (Lave and Wenger 1991) in more than one way. At least for newcomers, it might serve as an ideal learning environment in which situated learning can take place. Research schools at universities 
can be seen as these kind of communities. Universities of applied science may want to adapt this approach to applied scientific settings.

\section{Acknowledgements}

We would like to thank the ERASMUS programme and B\&O as well as from each of the educational institutions for financial support for this summer school. In addition we would like to acknowledge all the people who help in arranging all the practical details before, during the delivery of the summer school and reviewing earlier versions of this article. In particular, we would like to thank Beatriz Araújo, Paulo Azevedo, Nick Battle, Søren Bech, Adriana Lago de Carvalho, Jens Elsig, Kenneth Fiil, Dorthe Jensen, Christian Kleijn, Daniel Kopřiva, Erik Kristiansen, Kirsten Krogh, Charlotte Ladegaard, Natalie Linhartová, Janusz Pobożniak, Ove Poulsen, Else Skovgaard, Claus Monrad Spliid and Helle Stenholt.

\section{Notes}

1. It should be clear that there is a direct relation to the current limited durability of knowledge and lifelong learning.

2. The upcoming of mass education (Bransford et al. 2003, p. 132) in the modern age might have had a reinforcing effect on the typical role of teacher. At least back then, it seemed to have been an efficient way of dealing with a growing student population.

3. Value in the Valley, an (educational) innovation institute founded in 2005 by Hanze University Groningen and several of its Dutch educational partners, is having its main focus on innovation within the field of sustainable energy. It is located at a modern industrial site (instead of at a campus site).

4. TNO ICT is the ICT division of the Netherlands Organization for Applied Scientific Research. TNO ICT has a strong focus on concept development.

5. Visio Haren, a Dutch institute for the blind.

\section{References}

Bransford, J., Brown, A., Cocking, R., Donovan, M. and Pellegrino, J.E., 2003. How people learn: brain, mind, experience, and school. Expanded ed. National Academy Press: Washington, DC.

Caine, R., Caine, G., McClintic, C. and Klimek, K., 2005. 12 Brain/mind learning principles in action: the fieldbook for making connections, teaching, and the human brain. Corwin Press: California.

Calvano, C.N. and John, P., 2003. Systems engineering in an age of complexity. Systems Engineering, 7 (1), $25-34$.

Darsø, L., 2001. Innovation in the making. Thesis (PhD). Copenhagen Business School.

de Bono, E., 1985. Six thinking hats. Little, Brown and Company.

Dolmans, D.H., Grave, W.D., Wolfhagen, I. and van der Vleuten, C., 2005. Problem-based learning: future challenges for educational practice and research. Medical Education, 39 (7), 732-741.

Donovan, S. and Bransford, J.E., 2005. How students learn: history, mathematics, and science in the classroom. National Academies Press.

Ebert, C. and Neve, P.D., 2001. Surviving global software development. IEEE Software, 18 (2), $62-69$.

Hansen, M. and von Oetinger, B., 2001. Introducing T-shaped managers. Knowledge management's next generation. Harvard Business Review, 79 (3), 106-116.

Kelley, T. and Littman, J., 2005. The ten faces of innovation. Currency Doubleday: Boston, MA.

Lave, J. and Wenger, E., 1991. Situated learning: legitimate peripheral participation. Cambridge, UK: Cambridge University Press.

Lawson, B., 1980. How designers think. Architectual Press: London.

Lawson, B., 2004. What designers know. Architectual Press: London.

Lucena, J.C., 2006. Globalization and organizational change: engineers' experiences and their implications for engineering education. European Journal of Engineering Education, 31 (3), 321-338.

Major, C.H. and Palmer, B., 2001. Assessing the effectiveness of problem-based learning in higher education lessons from the literature. Academic Exchange Quarterly, 5 (1), 4-9.

Martin, R., Maytham, B., Case, J. and Fraser, D., 2005. Engineering graduates' perceptions of how well they were prepared for work in industry. European Journal of Engineering Education, 30 (2), 167-180.

Maskell, D.L., 1999. Student-based assessment in a multi-disciplinary problem-based learning environment. Journal of Engineering Education, 88 (2), 237-241.

Maskell, D.L. and Grabau, P.J., 1998. A multidisciplinary cooperative problem-based learning approach to embedded systems design. IEEE Transactions on Education, 41 (2), 101-103.

Savery, J.R., 2006. Overview of problem-based learning: definitions and distinctions. The Interdisciplinary Journal of Problem-based Learning, 1 (1), 9-20.

Seng, T., 2000. Thinking skills, creativity and problem-based learning. Proceedings of the 2nd Asia-Pacific Conference on Problem-Based Learning: Education Across Disciplines, Singapore, December 4-7, 2000. 
Skates, G.W., 2003. Interdisciplinary project working in engineering education. European Journal of Engineering Education, 28 (2), 187-201.

van Kasteren, J.M.N., 1996. Interdisciplinary teaching within engineering education. European Journal of Engineering Education, 21 (4), 387-392.

Zull, J., 2002. The art of changing the brain: enriching teaching by exploring the biology of learning. Stylus Publishing, LLC: Stirling.

\section{About the authors}

Peter Gorm Larsen is currently a professor at the Engineering College of Aarhus and in addition he holds an adjunct professorship position at the Aarhus University. After receiving his M.Sc. at the Technical University of Denmark in Electronic Engineering and Computer Science in 1988, he went to industry to bridge the gap between academia and industry. He later returned and did an industrial Ph.D. which was completed in 1995. He gave industrial courses all over the world, and had an industrial career until he decided to return to academia in 2005. His prime research interest is to improve the system engineering requiring cooperation between multiple disciplines to determine the optimal solution. He is the author of more than 60 papers published in journals, books and conference proceedings and a couple of books.

João M. Fernandes is an associate professor at the Dept. Informatics, Universidade do Minho. His research focuses in Software Engineering, and more particularly in Software Modeling, Requirements Engineering, and Embedded Software. In May 2000, he finished his Ph.D. dissertation, where he proposed a UML-based approach to develop embedded systems. From September 2002 until February 2003, he was a post-doctoral researcher at the Embedded Systems Laboratory, TUCS, in Turku, Finland, and from September 2006 until June 2007, he was an invited assistant professor at the Department of Computer Science, Aarhus University, Denmark. He is the author of more than 70 papers published in journals, books and conference proceedings.

Jacek Habel is currently a lecturer in the Department of Mechanical Engineering at Cracow University of Technology. He is also a director for teaching affairs in Production Engineering Institute. He received his MSc. in Automation \& Robotics in 1995, and his Ph.D. in Production Engineering in 2003, both at the same Cracow University of Technology. His scientific interest focusses on PLM design (Catia v5, Delmia, Smarteam) and manufacturing process planning (machining \& assembly processes, factory layout planning, etc.). He has also good experience in object-oriented programming and client/server database design.

Hanne Lehrskov is currently a lecturer in the Department of Architectural Engineering at the Engineering College of Aarhus. She received her MSc. in Architecture from the Aarhus School of Architecture. Her educational interests focus on architecture in relation to engineering issues as well as design method and innovation within the field of product design and architecture.

Richard J.C. Vos is currently a lecturer in the Department of Human Technology at the School of Engineering, Hanze University Groningen, University of Applied Sciences. He received his M.Sc. in experimental \& cognitive psychology from the University of Groningen. His educational interests focus on the application of insights from cognitive ergonomics and psychology to human technology interaction.

Oliver Wallington is educated as an Industrial Designer from Brunel University in the UK. Since graduation he has been a design contractor for ten years, undertaking design, concept, interaction and media projects for a broad range of clients including LEGO, GN Netcom and Danfoss. For the last four years he has been working at Bang \& Olufsen, mixing previous experience areas to develop digital technology product concepts. Products to market include LEGO Bionicle, LEGO Music Builder range and Bang \& Olufsen's BeoSound 5. Oliver has been representing the Industry side of things in a number of industry/academia collaborations. LEGO collaborations include joint development projects with MIT's Media Lab and for Bang \& Olufsen, he developed a number of strong university connections within Europe for internships, graduation and co-development projects. In addition to this, Oliver has been a guest lecturer and has been working with Danish Industry in developing better ties between Industry and Danish design schools.

Jan Zidek is currently a lecturer in the Department of Electrical Measurement at Faculty of Electrical Engineering and Computer Science, VSB - Technical University Ostrava. He has established this department in 1991 and has since then had a focus on virtual instrumentation and graphical programming. His prime interest is how to design and test mechatronics systems using software and hardware tools based on virtual instrumentation concept. 